\title{
VESTIBOLOGY
}

\section{Persistent postural perceptual dizziness following paroxysmal positional vertigo in migraine}

\section{La dizziness posturale percettiva persistente dopo vertigine posizionale parossistica nell'emicrania}

\author{
Paolo Tropiano, Luca Maria Lacerenza, Giovanni Agostini, Annalisa Barboni, Mario Faralli \\ Section of Otolaryngology-Head and Neck Surgery, Department of Surgical and Biomedical Sciences, University of Perugia, \\ Perugia, Italy
}

\section{SUMMARY}

Objective. This prospective study aimed to investigate the role of migraine in favouring the onset of persistent postural perceptual dizziness (PPPD) following paroxysmal positional vertigo (PPV).

Methods. A group of patients who came to our attention suffering of PPV with or without migraine and/or vestibular migraine (VM) was examined. Three months after the resolution, an anamnestic research was conducted aimed at establishing whether any patientrelated dizziness could meet the diagnostic criteria for PPPD.

Results. 12 of the 240 patients recruited met the diagnostic criteria for PPPD for an overall incidence of $5 \%$, with $3(1.85 \%)$ belonging to the non-migraine group and $9(11.5 \%)$ to the migraine group. In the latter, $6(28.6 \%)$ patients with VM and $3(5.26 \%)$ without VM were affected.

Conclusions. The study shows a significant increase of PPPD diagnosis in migraine compared to patients without migraine $(p=0.003)$. Within migraine there was a significant increase in those with VM compared to patients without VM $(p=0.0016)$. No difference emerged between patients without migraine and migraine patients without VM $(p>0.05)$. The presence of VM in patient's history, but not migraine without VM, appears to significantly increase the incidence of PPPD in patients with PPV.

KEY WORDS: PPPD, vestibular migraine, vestibular disorders, dizziness

\section{RIASSUNTO}

Obiettivo. Questo studio prospettico indaga il ruolo favorente dell'emicrania nell'insorgenza della dizziness percettiva posturale persistente (PPPD) dopo vertigine posizionale parossistica $(P P V)$.

Metodi. È stata esaminata una popolazione consecutiva di pazienti affetti da PPV, con o senza emicrania elo emicrania vestibolare (VM). Tre mesi dopo la risoluzione della PPV, è stata condotta una anamnesi volta a stabilire se una dizziness residua correlata al paziente potesse soddisfare i criteri diagnostici per la PPPD.

Risultati. 12 di 240 pazienti reclutati soddisfacevano i criteri diagnostici per la PPPD con un'incidenza complessiva del 5\%, 3 (1,85\%) appartenenti al gruppo non emicranico e $9(11,5 \%)$ a quello emicranico. Nello specifico, 6 pazienti $(28,6 \%)$ con VM e 3 senza VM $(5,26 \%)$ erano interessati.

Conclusioni. Lo studio mostra un aumento significativo della diagnosi di PPPD nell'emicrania rispetto ai pazienti senza $(p=0,003)$. Nell'emicrania c'è stato un aumento significativo in quelli con VM rispetto ai pazienti senza $(p=0,0016)$. Nessuna differenza è emersa tra i pazienti senza emicrania e pazienti emicranici senza VM $(p>0,05)$. La presenza di VM nella storia del paziente sembra aumentare significativamente l'incidenza di PPPD che si verifica in pazienti con $P P V$.

PAROLE CHIAVE: PPPD, emicrania vestibolare, disordini vestibolari, dizziness
Received: July 24, 2020

Accepted: November 27, 2020

\section{Correspondence}

Paolo Tropiano

Otorhinolaryngology Clinic, S.M. della Misericordia Hospital

via G. Dottori 1, 06100 S. Andrea delle Fratte,

Perugia, Italy

E-mail: tropianopaolo@gmail.com

Funding

None.

Conflict of interest

The Authors declare no conflict of interest.

How to cite this article: Tropiano P, Lacerenza LM, Agostini G, et al. Persistent postural perceptual dizziness following paroxysmal positional vertigo in migraine. Acta Otorhinolaryngol Ital 2021;41:263-269. https://doi. org/10.14639/0392-100X-N1017

() Società Italiana di Otorinolaringoiatria e Chirurgia Cervico-Facciale

\section{(c) (1) $(2)$}

This is an open access article distributed in accordance with the CC-BY-NC-ND (Creative Commons Attribution-NonCommercial-NoDerivatives 4.0 International) license. The article can be used by giving appropriate credit and mentioning the license, but only for non-commercial purposes and only in the original version. For further information: https:// creativecommons.org/licenses/by-nc-nd/4.0/deed.en 


\section{Introduction}

Persistent postural perceptual dizziness (PPPD) is classified as a chronic functional vestibular disorder ${ }^{1}$. It is not a structural or psychiatric condition, although both can coexist with the syndrome. Functional changes in postural control strategies ${ }^{2,3}$, shifts in multi-sensory information processing ${ }^{4}$ and reduced cortical integration of spatial orientation and threat assessment networks ${ }^{5}$ can be invoked in the pathophysiologic processes underlying PPPD. Recently, the diagnostic criteria for PPPD have been formulated in a consensus paper by the Barany society ${ }^{1}$. Although the term is new, PPPD collects aspects already described in various previous syndromes such as phobic postural vertigo ${ }^{6}$, space motion discomfort ${ }^{7}$, visual vertigo ${ }^{8}$ and subjective chronic dizziness ${ }^{9}$. PPPD may be precipitated by conditions that disrupt balance or cause vertigo, unsteadiness, or dizziness. These conditions include peripheral or central disorders, panic attacks or anxiety, concussive brain injuries, whiplash of the neck, autonomic disorders and medical illnesses ${ }^{9,10}$. The majority of conditions that precede PPPD are acute or episodic in nature and patients report the onset of chronic symptoms of PPPD following their acute illness ${ }^{1}$. Paroxysmal positional vertigo (PPV) is the most common peripheral vestibular disorder and is typically a recurrent vertigo with alternating active phases of the disease with intercritical periods of variable duration. Migraine is also often present in the history of a patient with recurrent vertigo. Migraine can even play a decisive pathogenetic role as it happens by definition in vestibular migraine ${ }^{11}$ or, alternatively, be a significant comorbidity as in Ménière's disease ${ }^{12}$. In PPV, in particular, migraine seems to condition a higher incidence ${ }^{13,14}$ and an earlier onset of the disease ${ }^{14}$. Therefore, if PPPD can be precipitated by an acute event in the course of a recurrent vestibulopathy, it is conceivable that migraine, if present, could condition this evolution. The initial purpose of this study was to ascertain the real existence of a clinical entity, which arose in the evolutionary stages of a recurrent vestibulopathy, capable of satisfying the diagnostic criteria for PPPD. Subsequently, the investigation was aimed at verifying a possible influence of migraine in determining the clinical feature. For this reason, a group of consecutive patients, who came to our attention suffering of PPV with or without migraine (M) and/or vestibular migraine (VM), was examined.

\section{Materials and methods}

277 consecutive patients (167 F, $110 \mathrm{M})$, between 18 and 65 years of age (age $46 \pm 12.4$ ), with a diagnosis of PPV made at our clinic in the period between 31 July 2017 and 31 January 2020 were evaluated. All patients were treated immediately with repositioning procedures after positional tests that led to the diagnosis of the disease. Positional tests were repeated 3-4 days later to verify the possible disappearance of the nystagmus and resolution of PPV ( $1^{\text {st }}$ control). If the control was negative, the diagnostic manoeuvres were re-programmed 7 days later to confirm the absence of the nystagmus ( $2^{\text {nd }}$ control). On this occasion, patients in whom the resolution of the PPV was confirmed again, were asked if there was a new condition of dizziness that arose after the disappearance of the nystagmus and currently present (Residual Dizziness: RD) ${ }^{15}$. In all patients, on the other hand, where diagnostic manoeuvres revealed the nystagmus at the $1^{\text {st }}$ or $2^{\text {nd }}$ control, repositioning manoeuvres were repeated and a new control was scheduled at 3-4 days until the nystagmus disappeared, according to our protocol (Fig. 1). A $3^{\text {rd }}$ control, three months after the $2^{\text {nd }}$ control, was performed in all patients who in the meantime had no other documented episodes of PPV. Confirmed the absence of nystagmus and the resolution of PPV by performing positional tests, patients who had reported RD were asked again if this condition was still present. To complete the investigation, an anamnestic research was conducted aimed at establishing whether any patient-related dizziness, not identifiable in the typical vertigo crisis of PPV, could meet the diagnostic criteria for PPPD ${ }^{1}$ (Tab. I). The time interval established in this protocol is justified by the minimum duration of the required dizziness according to the diagnostic criteria for PPPD. All patients who, in the time interval between the $2^{\text {nd }}$ and $3^{\text {rd }}$ control, had a new episode of PPV confirmed by the repetition of the diagnostic manoeuvres, were excluded from the study. Patients with a history of vestibular neuritis and suffering from Ménière's disease and central vestibular disorders were excluded. Patients over the age of 65 were also excluded. The latter criterion has been adopted as it is considered a less likely influence of the pathogenetic mechanism of migraine with advancing age ${ }^{16}$. Finally, patients with post-traumatic PPV were excluded, as the injury itself can cause PPPD ${ }^{1}$. To avoid an inclusion of pre-existing PP$\mathrm{PD}$, only patients without persistent dizziness, unsteadiness or non-spinning vertigo in the three months preceding the PPV attack were recruited. Of the five criteria that define PPPD, we only considered the quality of the symptom at the first observation ${ }^{1}$. Since all criteria must be fulfilled for a diagnosis of PPPD, the absence of one symptom consequently excludes the diagnosis. Based on the natural history of the disease, patients were divided into 2 groups: Group A and Group B. Group A includes patients in whom PPV, documented in the study, was the first and only episode in life. Group B includes patients in whom PPV, documented in the study, did not represent the first and only episode, and therefore having a recurrent trend. This definition indi- 


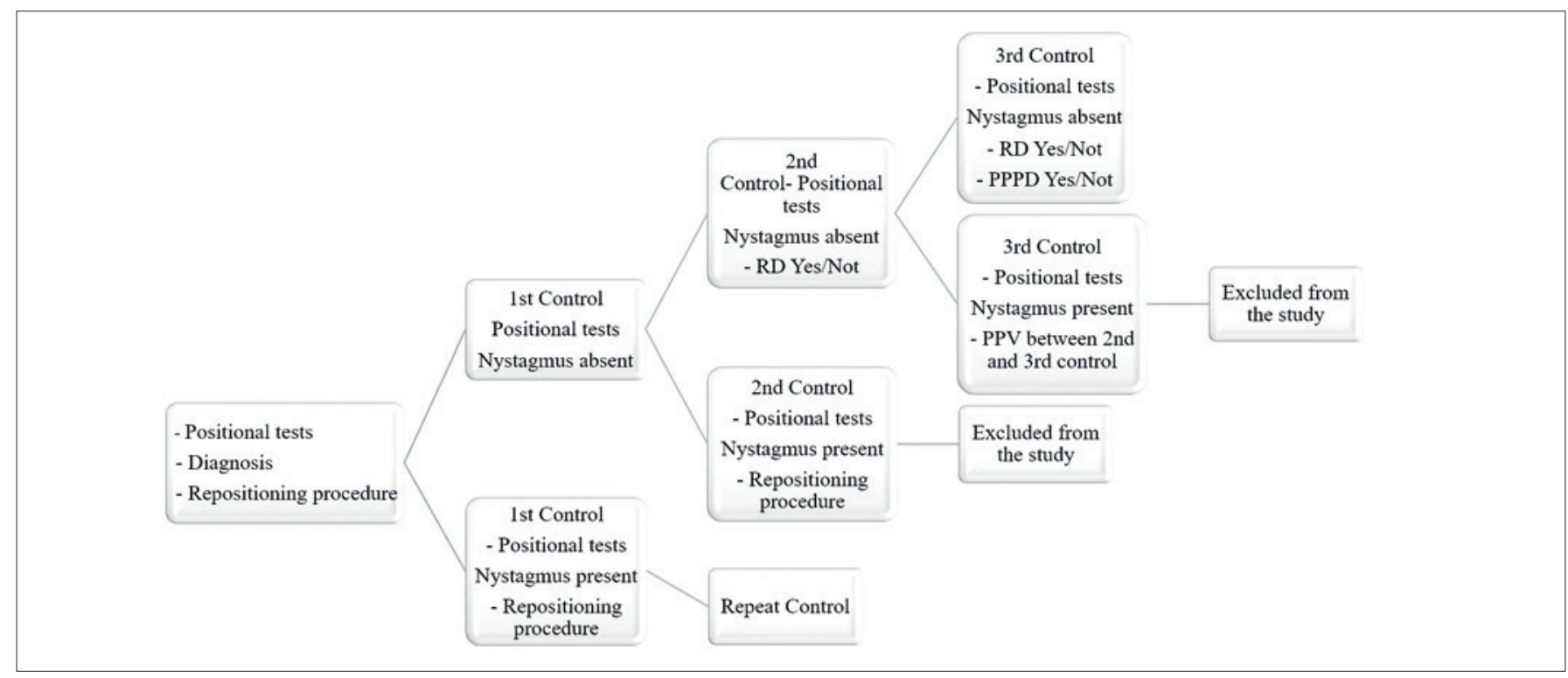

Figure 1. Inclusion criteria in the study of patients with paroxysmal positional vertigo (PPV).

Table I. Criteria for the diagnosis of persistent postural-perceptual dizziness (PPPD): all five criteria must be fulfilled to make the diagnosis.
A. One or more symptoms of dizziness, unsteadiness, or non-spinning vertigo are present on most days for 3 months or more:
1. Symptoms last for prolonged (hours long) periods of time, but may wax and wane in severity
2. Symptoms need not be present continuously throughout the entire day
B. Persistent symptoms occur without specific provocation, but are exacerbated by three factors:
1. Upright posture
2. Active or passive motion without regard to direction or position, and
3. Exposure to moving visual stimuli or complex visual patterns
C. The disorder is precipitated by conditions that cause vertigo, unsteadiness, dizziness, or problems with balance including acute, episodic, or chronic vestibular syndromes, other neurologic or medical illnesses, or psychological distress:
1. When the precipitant is an acute or episodic condition, symptoms settle into the pattern of criterion A as the precipitant resolves, but they may occur intermittently at first, and then consolidate into a persistent course
2. When the precipitant is a chronic syndrome, symptoms may develop slowly at first and worsen gradually
D. Symptoms cause significant distress or functional impairment
E. Symptoms are not better accounted for by another disease or disorder

cates a PPV with at least two documented active phases of the disease with a free interval lasting at least three months. In all patients recruited, the number of therapeutic sessions necessary to obtain the disappearance of the nystagmus and the resolution of the PPV was calculated. Based on whether or not a current or previous history of migraine (M) with or without aura according to the International Classification of Headache Disorders (ICHD) ${ }^{17}$, patients were divided into group $\mathrm{M}$ and group $\mathrm{nM}$ respectively. Group $\mathrm{M}$ patients were in turn divided into group VM/M if the diagnostic criteria of the VM defined by the Barany Society ${ }^{11}$ were met, and group $n V M / M$ if the same criteria were not fulfilled. The results emerged were compared with those of a control group of 52 consecutive patients (average age $44.5 \pm 7.2$ ) affected by VM of our database without history for PPV (group VM/
nPPV). The study was conducted at the Department of Surgical and Biomedical Sciences, Section of OtolaryngologyHead and Neck Surgery of the University of Perugia (Italy). The authors assert that all procedures contributing to this work comply with the ethical standards of the relevant national and institutional guidelines on human experimentation and with the Helsinki Declaration of 1975, as revised in 2008. Informed consent was obtained from all participants in the study.

\section{Statistical analyses}

The incidence of PPPD in the population of patients with PPV examined in the study was calculated and the prevalence of PPPD within the groups considered. The statistical comparison between the percentage values was carried 
out by means of chi-square test alone and with Yates correction where considered necessary. Parametric t-test was performed for the comparison between means and standard deviations. The significance level was set at $p<0.05$.

\section{Results}

Of the 277 patients initially evaluated, 12 were excluded because they suffered from Ménière's disease (MD) (6 patients), neuritis vestibularis (NV) (2 patients) and central vestibular disorders (4 patients). 17 patients were excluded as they presented a new episode of PVV between the $2^{\text {nd }}$ and $3^{\text {rd }}$ control. Finally, 8 patients did not show up for the final evaluation on the occasion of the $3^{\text {rd }}$ control. Therefore, 240 patients were definitively recruited in the present survey, $124(51.7 \%)$ in group A and 116 in group B (48.3\%). 78 patients belonged to the $\mathrm{M}$ group and 162 to the $\mathrm{nM}$ group. Within group M, 21 patients were affected by VM (group $\mathrm{VM} / \mathrm{M}$ ) and 57 patients, on the contrary, did not meet the diagnostic criteria for VM (group nVM/M). The patients who reported RD were $97(40.4 \%)$ at the $2^{\text {nd }}$ control. 34 of these patients continued to report RD on the $3^{\text {rd }}$ control. 12 of the 240 patients recruited met the diagnostic criteria for PPPD for an overall incidence of $5 \%$ (Fig. 2). In any case, the diagnosis of PPPD concerned patients who reported RD during the $2^{\text {nd }}$ and $3^{\text {rd }}$ control. Within these, the incidence of the PPPD was $12.4 \%$ (12/97) and 35.3\% (12/34), respectively (Fig. 2). This difference is significant $(\mathrm{p}<0.05)$ both by the chi-square test alone ( $\mathrm{p}=0.000000272)$ and by the chisquare test with Yates correction ( $\mathrm{p}=0.000001353)$. In 10 cases $(8.1 \%)$, the diagnosis of PPPD concerned group A and in 2 cases $(1.72 \%)$ patients in group B. The chi-square test $(\mathrm{p}=0.040)$ showed a significantly higher incidence of PPPD in group A compared to group B $(\mathrm{p}<0.05)$. The distribution of PPPD within the groups considered with reference

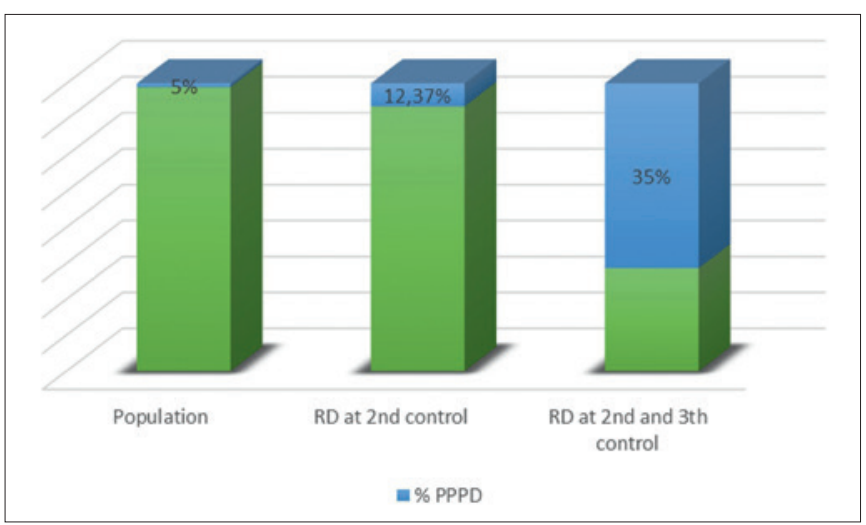

Figure 2. Incidence of persistent postural perceptual dizziness (PPPD) in all groups.

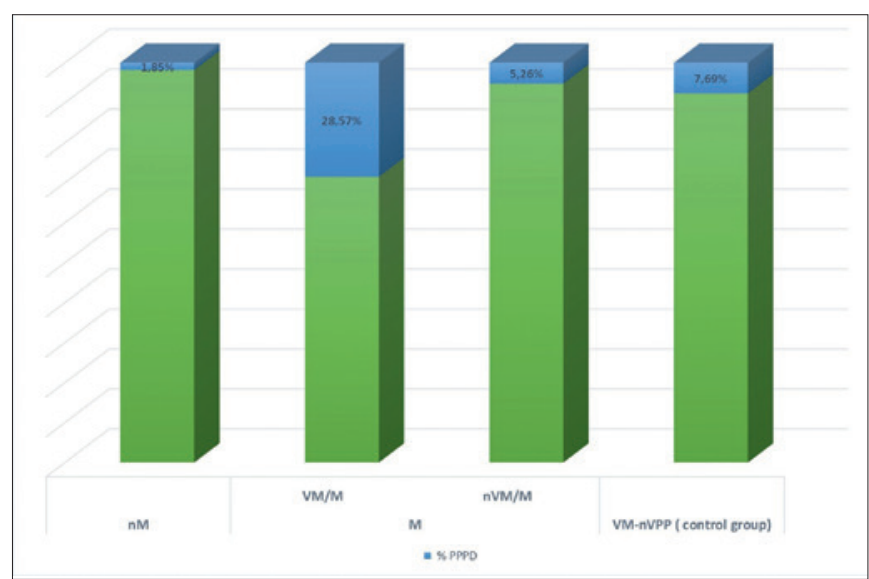

Figure 3. Incidence of persistent postural perceptual dizziness (PPPD) in groups with or without migraine.

to $\mathrm{M}$ was as follows: 3 patients $(1.85 \%)$ in group $\mathrm{nM}$ and 9 patients $(11.5 \%)$ in group $M$. In the latter, the distribution of PPPD with reference to VM was as follows: 3 patients $(5.26 \%)$ in the nVM/M group and $6(28.6 \%)$ patients in the VM/M group. Chi-square test showed a significant increase of PPPD diagnosis in group $\mathrm{M}$ compared to group $\mathrm{nM}$ $(\mathrm{p}=0.0016)$. With Yates correction the $p$-value is 0.0046 , thus significant at $\mathrm{p}<0.05$. Within group $\mathrm{M}$ there was a significant increase in PPPD in group VM/M compared to group $\mathrm{nVM} / \mathrm{M}$. The chi-square statistic test is 7.22556391 . The $\mathrm{p}$-value is 0.0072 , and significant at $p<0.05$. Even with Yates correction (5.35) the $p$-value is 0.021 . Equally very significant was the increase in the incidence of PPPD in the $\mathrm{VM} / \mathrm{M}$ group compared to the $\mathrm{nM}$ group with or without Yates correction $(p<0.000003)$. No significant difference emerged from comparison with the chi-square test between group $\mathrm{nM}$ and group $\mathrm{nVM} / \mathrm{M}(p>0.05) .4$ patients (7.7\%) belonging to the VM/ nPPV group (control group) met the diagnostic criteria for PPPD (Fig. 3). In this group, the incidence of PPPD was significantly higher $(p=0,043)$ compared to the $\mathrm{nM}$ group (chi-square) and significantly lower ( $p=0.03$ ) compared to the VM/M group. No significant difference emerged between VM/nPPV and nVM/M $(p>0.05)$. The number of therapeutic sessions necessary to obtain the resolution of PPV was $1.54 \pm 0.87$. No significant difference $(p>0.05)$ emerged between patients fulfilling PPPD criteria $(1.56 \pm 0.76)$ and those not fulfilling it $(1.53 \pm 0.71)($ Tab. II).

\section{Discussion}

The data from our study confirms that the vertigo attacks that characterise the PPV can constitute precipitating conditions that precede the PPPD ${ }^{18}$, although the overall inci- 
Table II. The incidence of persistent postural perceptual dizziness (PPPD) within the groups examined.

\begin{tabular}{|c|c|c|c|c|}
\hline Groups & PPPD & $\%$ PPPD & $\chi 2$ (chi- square value) & $\mathrm{p}$ value $(<0.05)$ \\
\hline Group A & 10 & $8.10 \%$ & 4.82 & 0.04 \\
\hline Group B & 2 & $1.72 \%$ & & \\
\hline Group M & 9 & $11.50 \%$ & 9.88 & 0.0016 \\
\hline Group nM & 3 & $1.85 \%$ & & \\
\hline Group VM/M & 6 & $28.60 \%$ & 7.22 & 0.0072 \\
\hline Group nVM/M & 3 & $5.26 \%$ & & \\
\hline Group VM/M & 6 & $28.60 \%$ & 26.99 & 0.00000020 \\
\hline Group nM & 3 & $1.85 \%$ & & \\
\hline Group nVM/M & 3 & $5.26 \%$ & 1.79 & 0.18 \\
\hline Group nM & 3 & $1.85 \%$ & & \\
\hline Group VM/nPPV (control group) & 4 & $7.70 \%$ & 4.76 & 0.03 \\
\hline Group VM/M & 6 & $28.60 \%$ & & \\
\hline Group VM/nPPV (control group) & 4 & $7.70 \%$ & 4.11 & 0.043 \\
\hline Group nM & 3 & $1.85 \%$ & & \\
\hline Group VM/nPPV (control group) & 4 & $7.70 \%$ & 0.25 & 0.62 \\
\hline Group nVM/M & 3 & $5.26 \%$ & & \\
\hline Group RD $2^{\text {nd }}$ control & 97 & $12.40 \%$ & 26.4 & 0.00000027 \\
\hline Group RD $2^{\text {nd }}$ and $3^{\text {rd }}$ control & 34 & $35.30 \%$ & & \\
\hline
\end{tabular}

dence is low. However, some features are worthy of further analysis. First of all, the incidence of PPPD is more relevant when referring to post-PPV RD. Although repositioning procedures are usually very effective in improving vertigo, some patients report, for a certain period afterward, imbalance without positional vertigo, named RD. The pathogenesis of the RD is still debated ${ }^{19,20}$. In most cases there is a spontaneous resolution in a variable time, from days to weeks ${ }^{21}$, which is also confirmed by our study. In presence of long-term dizziness, when PPPD is suspected, the diagnosis can be made by targeted and accurate medical history, and investigating the elements that meet the diagnostic criteria. The diagnosis of PPPD concerned patients who reported a dizziness of at least three months, after resolution of a PPV episode, representing 30\% of these cases. Another interesting aspect concerning the natural history of the PPV is that the PPPD mainly involved patients who had the first episode of PPV. This probably represents a completely new experience for the patient, with a strong emotional impact. In recurrent PPV, on the contrary, the patient undergoes a weaker surprise effect and appears more reassured in case of recurrence of the vertigo. Moreover, being aware of the symptom and its modality of appearance, the patient tends to avoid critical situations and movements capable of causing vertigo. On the contrary, a greater resistance to therapeutic manoeuvres, expressed by the number of sessions that are necessary to obtain the resolution of the nystagmus, does not imply a favourable condition for the appearance of PPPD. The main goal of our study was to verify the influence of migraine as a trigger for the PPPD onset, following vertigo attacks induced by cupulo-canalolithiasis. For this purpose, we investigated patients affected by PPV and migraine, with or without VM. It should be noted that patients suffering from VM have different clinical features from those with PPV with or without migraine. At the same time, however, migraine seems to condition a higher incidence of PPV ${ }^{14}$ and VM undeniably accounts for a large share in migraine women ${ }^{11}$. Therefore, it is common to find patients with migraine presenting distinct episodes of PVV or attacks of VM over the course of their life. Assuming a greater involvement of the vestibular system in these patients, they represent an ideal study group in which to test the influence of migraine in the induction of PPPD after PPV. On the other hand, a control study was carried out with a group of patients suffering from VM without previous or current history of PPV. The data from the study clearly indicate a significant role of migraine in its globality. In particular, patients who suffer from VM appear to be more prone to the pathogenetic mechanism triggered by migraine that lead to PPPD. In other words, migraine alone does not seem to exert a significant influence, but a concomitant weakness of the vestibular system is required. To confirm this finding is the evidence of a significantly higher incidence of PPPD in VM/ nPPV group compared to $\mathrm{nM}$ group, which in turn is not different from the $\mathrm{nVM}$ / Mgroup. If patients who suffer from VM have a higher 
probability of experiencing PPPD, there is no doubt that in these patients the probability of experiencing PPPD is even higher if there is a concomitant PPV. The appearance of a vertigo with different characteristics from those to which the patient suffering from VM is used to, probably constitutes an element of novelty and alarm that is able to trigger a new condition of uncertainty that leads to PPPD. Several mechanisms could explain this diversity.

Referring to the definition of PPPD, there are two aspects that emerge from the literature: anxiety and visual dependence. Previous studies have indicated the importance of anxious personality traits as possible risk factors ${ }^{6}$. Two elements show relevant importance for the initial pathological response: a high level of anxiety and a mental status characterised by an exaggerate vigilance towards acute symptoms generated by the precipitating events of PPPD ${ }^{1,4}$. In 1995, Bronsteim described the symptom of VV in a portion of patients in his tertiary otoneurologic clinic ${ }^{8}$. People with VV manifested visual dependence, a trait-like tendency to rely on visual information for spatial orientation. Both of these factors can be favoured by migraine mechanisms. Previous studies, performed in patients with most common vestibulopathies, have shown that PPV is accompanied by lower anxiety levels than those found in VM and Ménière's disease ${ }^{22}$. As said, in fact, there is a self-control in PPV by patients who are able to prevent crises during the active phase, avoiding those cephalic movements triggering dizziness they have learned to know. On the other hand, this protective mechanism is completely missing in VM, in which the attacks are completely unpredictable and uncontrollable. This inevitably has different emotional repercussions. The interaction between migraine and anxiety has been found. During migraine attack, an increased release of neurotransmitters including 5-hydroxytryptophan, noradrenaline and dopamine (probably accompanied by other mechanisms such as calcium channel disorders in brain and inner ear) might be responsible for symptoms like headache and vertigo ${ }^{23}$. These neurotransmitters play a crucial role in anxiety and depression ${ }^{24}$. Moreover, visual induced vertigo is among the symptoms considered in the diagnostic criteria of VM and it has, in the context of pleomorphism of the disease, a significant impact in terms of frequency and symptomatology ${ }^{11}$. To strengthen the hypothesis of a visual dependence and a possible role in the determinism of PPPD in migraine subjects, there is an element that emerged in our previous study concerning the prolonged effects of an optokinetic stimulation on the postural control of migraine patients. The Sway area values, in fact, are constantly higher in patients that suffer from migraine, and even more in those affected by VM after 60 minutes away from the optokinetic stimulation compared to the controls ${ }^{25}$. Although a visual dependence has also been hypothesised in PPV in the phases following the disappearance of the nystagmus ${ }^{26}$, it is reasonable to assume that this may be responsible for many cases of RD with spontaneous resolution, while a further evolution towards the PPPD requires enhancement of the same by migraine mechanisms.

\section{Conclusions}

PPPD may be precipitated by PPV, especially following the first crises. Careful anamnestic history aimed at identifying the diagnostic criteria of PPPD is required in patients with long-term post-PPV RD. The presence of VM appears to significantly increase the incidence of PPPD in patients with PPV. Anxiety and visual dependence, worsened by migraine, may be the main factors that increase this risk.

\section{References}

1 Stabb JP, Eckhardt-Henn A, Horii A, et al. Diagnostic criteria for persistent postural-perceptual dizziness (PPPD): Consensus document of the committe for the classification of the vestibular disorders of the Barany Society. J Vestib Res 2017;27:191-208. https://doi. org/10.3233/VES-170622

2 Holmberg J, Tjernstrom F, Karlberg M, et al. Reduced postural differences between phobic postural vertigo patients and healthy subjects during a postural threat. J Neurol 2009;256:1258-1262. https://doi. org/10.1007/s00415-009-5110-X

3 Schniepp R, Wuehr M, Huth S, et al. Gaits characteristics of patients with phobic postural vertigo: effects of fear of falling, attention, and visual input. J Neurol 2014;261:738-746. https://doi.org/10.1007/ s00415-014-7259-1

4 Cousins S, Kasky D, Cutfield N, et al. Predictors of clinical recovery from vestibular neuritis: a prospective study. Ann Clin Transl Neurol 2017;4:340-346. https://doi.org/10.1002/acn3.386

5 Indovina I, Riccelli R, Chiarella G, et al. Role of the insula and vestibular system in patients with chronic subjective dizziness: an fMRI study using sound-evoked vestibular stimulation. Front Behav Neurosci 2015;9:334. https://doi.org/10.3389/fnbeh.2015.00334

6 Brandt T. Phobic postural vertigo. Neurology 1996;46:1515-1519. https://doi.org/10.1212/wnl.46.6.1515

7 Jacob RG, Redfern MS, Furman JM. Space and motion discomfort and abnormal balance control in patients with anxiety disorders. J Neurol Neurosurg Psychiatry 2009;80:74-78. https://doi.org/10.1136/ jnnp.2007.136432

8 Bronsteim AM. Visual vertigo syndrome: clinical and posturography findings. J Neurol Neurosurg Psychiatry 1995;59:472-476. https:// doi.org/10.1136/jnnp.59.5.472

9 Staab JP, Ruckenstein MJ. Expanding the differential diagnosis of dizziness. Arch Otolaryngol Head Neck Surg 2007;133:170-176. https://doi.org/10.1001/archotol.133.2.170

10 Staab JP, Eggers S, Neff B, et al. Validation of a clinical syndrome of persistent dizziness and unsteadiness. Abstracts from the XXVI Barany Society Meeting, Reykjavik, Iceland, August 18-21, 2010. J Vest Res 2010;20:172-173.

11 Lempert T, Olesen J, Furman J, et al. Vestibular migraine: diagnostic criteria. Consensus document of the Barany Society and the International Headache Society. J Vestib Res 2012;22:167-172. https://doi. org/10.1007/s00115-013-3768-x 
12 Radtke A, Lempert T, Gresty MA, et al. Migraine and Ménière's disease: is there a link? Neurology 2002;59:1700-1704. https://doi. org/10.1212/01.wnl.0000036903.22461.39

13 Kim SK, Hong SM, Park IS, et al. Association between migraine and benign paroxysmal positional vertigo among adults in South Korea. JAMA Otolaryngol Head Neck Surg 2019;145:307-312. https://doi. org/10.1001/jamaoto.2018.4016

14 Ishiyama A, Jacobson KM, Baloh RW. Migraine and benign positional vertigo. Ann Otol Rhinol Laryngol 2000;109:377-380. https://doi. org/10.1177/000348940010900407

15 Seok JI, Lee HM, Yoo JH, et al. Residual dizziness after successful repositioning treatment in patients with benign paroxysmal positional vertigo. J Clin Neurol 2008;4:107-110. https://doi.org/10.3988/ jcn.2008.4.3.107

16 Dahlöf CGH, Johansson M, Casserstedt S, et al. The course of frequent episodic migraine in a large headache clinic population: a 12-year retrospective follow-up study. Headache 2009;49:1144-1152. https://doi.org/10.1111/j.1526-4610.2009.01502.x

17 Headache Classification Committee of the International Headache Society (IHS). The International Classification of Headache Disorders, $3^{\text {rd }}$ edition. Cephalalgia 2018;38:1-211. https://doi. org/10.1177/0333102417738202

18 Von Brevern M, Bertholon P, Brandt T, et al. Benign paroxysmal positional vertigo: diagnostic criteria. Consensus document of the committee for the Classification of Vestibular Disorders of the Barany Society. J Vestib Res 2015;25:105-117. https://doi.org/10.1016/j. otorri.2017.02.007

19 Teggi R, Quaglieri S, Gatti O, et al. Residual dizziness after successful repositioning manuevers for idiopathic benign paroxysmal po- sitional vertigo. ORL J Otorhinolaryngol Relat Spec 2013;2:74-81. https://doi.org/10.1159/000350255

20 Dispenza F, Mazzucco W, Mazzola S, et al. Observational study on risk factors determining residual dizziness after successful benign paroxysmal positional vertigo treatment: the role of subclinical BPPV. Acta Otorhinolaryngol Ital 2019;39:347-352. https://doi. org/10.14639/0392-100X-2247

21 Faralli M, Lapenna R, Giommetti G, et al. Residual dizziness after the first BPPV episode: role of otolithic function and of a delayed diagnosis. Eur Arch Otorhinolaryngol 2016;273:3157-3165. https:// doi.org/10.1007/s00405-016-3947-z

22 Yuan Q, Yu L, Shi D, et al. Anxiety and depression among patients with different types of vestibular peripheral vertigo. Medicine 2015;94: e453. https://doi.org/10.1097/MD.0000000000000453

23 Cutrer FM, Baloh RW. Migraine-associated dizziness. Headache 1992;32:300-304. https://doi.org/10.1111/j.1526-4610.1992. hed3206300.x

24 Balaban CD, Jacob RG, Furman JM. Neurologic bases for comorbidity of balance disorders, anxiety disorders and migraine: neurotherapeutic implications. Expert Rev Neurotherap 2011;11:379-394. https://doi.org/10.1586/ern.11.19

25 Panichi R, Cipriani L, Sarchielli P, et al. Balance control impairment induced after OKS in patients with vestibular migraine: an intercritical marker. Eur Arch Otorhinolaryngol 2014;120:24-30. https://doi. org/10.1007/s00405-014-3179-z

26 Agarwal K, Bronstein AM, Faldon ME, et al. Visual dependence and BPPV. J Neurol 2012;259:1117-1124. https://doi.org/10.1007/ s00415-011-6311-7 